\title{
A simple intervention to reduce your chance of missing an acute aortic dissection
}

\author{
Robert Ohle, $\mathrm{MBBCh}^{*}$; Sarah Mc Isaac, $\mathrm{MBBCh}^{\dagger}$; Jeffrey J. Perry, MD
}

\section{CLINICIAN'S CAPSULE}

What is known about the topic?

Acute aortic dissection is rare, but often fatal; we are unsure who to image; and we miss one in five cases.

What did this study ask?

Is the quality of history taking associated with misdiagnosis of an acute aortic dissection?

What did this study find?

Physicians who asked more common pain questions (character, onset, severity, duration, and radiation) had a better initial identification of cases.

Why does this study matter to clinicians?

A complete and focused history could reduce your chance of missing an acute aortic dissection.

\section{ABSTRACT}

Introduction: Acute aortic dissection (AAD) is a time sensitive, difficult to diagnose, aortic emergency. We sought to explore the quality of history taking in AAD and assess its impact on misdiagnosis.

Methods: We studied a retrospective cohort of patients $>18$ years old who presented to two tertiary care emergency departments from January 1st 2004 - December $31^{\text {st }} 2012$ and were diagnosed with an acute aortic dissection (AAD) on CT, MRI or TEE. Trained reviewers' extracted data using a standardized data collection form. The definitions of 5 pain characteristics - character, onset, duration, quality, and radiation were defined a priori.

Results: Data were collected for 194 cases of acute aortic dissection with a mean age of 65 (SD 14.1) and $66.7 \%$ male, 34 $(17.6 \%)$ missed on initial presentation. Only 20(14.8\%) patients were asked all 5 questions. The most common initial incorrect diagnosis were acute coronary syndrome $(16,47 \%)$, pulmonary embolism $(5,14.7 \%)$ and stroke $(4,11.7 \%)$. If <2 questions were asked 1 in 5 cases were missed, 4 times greater than if $>2$ were asked $(P<0.01)$.
Conclusion: Clinicians should ask and document the character, onset, duration, radiation and severity of pain in any patient presenting with chest, abdominal or flank pain. A focused history still remains the keystone to reducing misdiagnosis.

\section{RÉSUMÉ}

Introduction: La dissection aiguë de l'aorte (DAA) est une urgence vasculaire difficile à diagnostiquer, dans laquelle le temps compte. L'étude décrite ici visait à évaluer la qualité de l'anamnèse dans la DAA et son incidence sur les diagnostics erronés.

Méthode: Il s'agit d'une étude rétrospective de cohortes composées de patients $>18$ ans qui ont consulté dans deux services des urgences de soins tertiaires, du $1^{\mathrm{er}}$ janvier 2004 au 31 décembre 2012, et chez qui a été posé un diagnostic de DAA à l'aide de la TDM, de I'IRM ou de l'échocardiographie transœsophagienne. Des examinateurs formés ont procédé à l'extraction de données à l'aide d'un formulaire uniforme de collecte de renseignements. Cinq descripteurs ont été utilisés au départ pour définir la douleur : le caractère, le début, la durée, la qualité et l'irradiation.

Résultats: La collecte de donnée a permis de recenser 194 cas de dissection aiguë de l'aorte; I'âge moyen était de 65 ans (écart type : 14,1 ) et il y avait $66,7 \%$ d'hommes; il y a eu erreur de diagnostic à la première consultation dans 34 cas $(17,6 \%)$. Les 5 questions sur la douleur avaient été posées à 20 patients $(14,8 \%)$ seulement. Les diagnostics erronés les plus fréquents étaient le syndrome coronarien aigu (16; 47\%), l'embolie pulmonaire $(5 ; 14,7 \%)$ ou l'accident vasculaire cérébral $(4 ; 11,7 \%)$. Le fait de poser $<2$ questions a été associé à un risque de diagnostic erroné dans 1 cas sur 5 , soit un risque 4 fois supérieur à celui enregistré dans les cas où $>2$ questions avaient été posées $(p<0,01)$.

Conclusion: Les cliniciens devraient poser des questions sur le caractère, le début, la durée, l'irradiation et l'intensité de la douleur, et consigner les renseignements recueillis au dossier,

From *Department of Emergency Medicine, Health Science North Research Institute, Northern Ontario School of Medicine, Sudbury, ON; †Department of Critical Care, Department of Anaesthesia, Health Science North Research Institute, Northern Ontario School of Medicine, Sudbury, ON; and the $\ddagger$ Department of Emergency Medicine, the Ottawa Hospital Research Institute, University of Ottawa, Ottawa, ON.

Correspondence to: Dr. Robert Ohle, Health Science North Research Institute, 41 Ramsey Lake Road, Sudbury, ON K1Y 4E9; Email: Robert.ohle@ gmail.com

(C) Canadian Association of Emergency Physicians 
chez tout patient qui consulte pour des douleurs thoraciques, abdominales ou du flanc. Une anamnèse précise reste encore la meilleure arme contre le risque de diagnostic erroné.
Keywords: Aortic dissection, diagnostic accuracy, history taking

\section{INTRODUCTION}

Acute aortic dissection (AAD) is the most common aortic catastrophe, and one in five are missed on the first presentation, resulting in increased morbidity and mortality. ${ }^{1,2}$ In the age of clinical decision rules, aortic dissection has been identified as a priority for development. ${ }^{3} \mathrm{Com}-$ puted tomography (CT), ordered to rule out aortic dissection, has increased in the past number of years, and a staggering $98 \%$ of these are negative. ${ }^{2,4}$ With easier access to imaging, are we focusing less time on history?

We sought to explore the quality of history taking for those diagnosed with $\mathrm{AAD}$ and assess its impact on misdiagnosis.

\section{METHODS}

\section{Study population}

We included patients aged $>18$ years who presented to two tertiary care emergency departments (ED) or a regional cardiac referral centre from 2002 to 2014 with acute ( $<14$ days) onset of non-traumatic abdominal/ back/chest/flank pain (truncal pain) and a new diagnosis of AAD. Cases were identified and enrolled through the $\mathrm{ED}$, in hospital, or by a death certificate diagnosis of aortic dissection, intramural hematoma, or penetrating atherosclerotic ulcer.

We excluded patients with trauma within 24 hours of pain onset or known AAD. Data were extracted per guidelines put forward by Jansen et al. ${ }^{3}$ Extracted data were verified in multiple sources including the ED record of treatment, consultant notes, and integrated progress notes. Four trained reviewers extracted data using standardized paper data forms. The kappa statistic for inter-observer agreement was calculated, with the data extraction form being considered a single variable. If extraction of any variable on the form varied between reviewers, then it was counted as a disagreement; if all variables on the form were identically extracted, then that data form was counted as agreement.

\section{Outcome measures}

$\mathrm{AAD}$ was defined based on radiological evidence of aortic dissection; intramural hematoma; or penetrating atherosclerotic ulcer on CT, magnetic resonance imaging (MRI), or transesophageal echocardiography (TEE). A missed case of $\mathrm{AAD}$ was defined by failure to diagnose within the ED, treatment for an alternative diagnosis (i.e., anticoagulation for a pulmonary embolism) within the ED, or re-presentation within 14 days of the initial visit with a new diagnosis of $\mathrm{AAD}$.

\section{Variables}

ED records were evaluated for documentation of queries related to five descriptors of pain: character, onset, duration, severity, and radiation. These variables were chosen following a comprehensive systematic review of literature for statistically significant clinical findings, as well as consensus of the senior study team (practicing certified emergency medicine physicians) that the variables were clinically significant. ${ }^{2,5,6}$ See the appendix for the definitions of the variables.

\section{Data analysis}

Extracted clinical variables were entered into an electronic database. First, descriptive statistics including means, medians, the standard deviation for continuous variables, and percentages for dichotomous variables were calculated. Variables were assessed for association with missed $\mathrm{AAD}$ in a univariate analysis.

Continuous variables were compared using a twosided Student $t$ test for normal distributions and the Mann-Whitney $U$ test for non-normal distributions. Categorical variables were compared using a chi-square or Fisher's exact test, as appropriate. The analysis was performed using SAS 9.4 University Edition. This study was approved by the institutional review board of the Ottawa Hospital. 


\begin{tabular}{|c|c|c|c|c|}
\hline Characteristics & Diagnosed (160) & Missed (34) & Sensitivity $(95 \% \mathrm{Cl})$ & $p$ value \\
\hline Mean (standard deviation); age (years) & $65.2(14.2)$ & $65.6(13.8)$ & & 0.2 \\
\hline Male & $105(65.6)$ & $22(64.7)$ & & 0.19 \\
\hline \multicolumn{5}{|l|}{ Aortic dissection } \\
\hline Type A & $86(53.7)$ & $28(82.4)$ & & 0.02 \\
\hline Type B & $74(46.3)$ & $6(17.6)$ & & 0.01 \\
\hline \multicolumn{5}{|l|}{ Pain descriptors } \\
\hline Severe & $54(34)$ & $4(12)$ & & 0.01 \\
\hline Abrupt onset pain & $139(87.4)$ & $29(91.2)$ & & 0.54 \\
\hline Radiating pain & $121(76)$ & $24(71)$ & & 0.5 \\
\hline Character & $124(78)$ & $30(88.2)$ & & 0.18 \\
\hline Duration & $47(29.6)$ & $3(8.8)$ & & 0.012 \\
\hline \multicolumn{5}{|l|}{ Number of questions } \\
\hline $0-1$ & $13(8.2)$ & $2(5.9)$ & $84.4(58.3-94.4)$ & 0.65 \\
\hline 2 & $97(61)$ & $28(82.3)$ & $77.4(69.3-83.9)$ & 0.018 \\
\hline 3 & $5(3.1)$ & $1(2.9)$ & 78.6 (37.6-95.7) & 0.95 \\
\hline 4 & $24(15.1)$ & $1(2.9)$ & 94.2 (75.9-98.8) & 0.055 \\
\hline 5 & 19 (11.9) & $1(2.9)$ & $98.4(92.4-99.7)$ & 0.12 \\
\hline$>2$ & $48(30.1)$ & $3(8.8)$ & $93.3(82.4-97.6)$ & 0.01 \\
\hline
\end{tabular}

\section{RESULTS}

Data were collected from 2002 to 2014, yielding 194 cases of AAD, with a mean age of 65 years (standard deviation [SD] 14.1), and $66.7 \%$ were male (Figure A-1, Table 1). The kappa after chart training was 0.85 , and for study data extraction, it was 0.91 . Of the 194 cases of AAD, $34(17.6 \%)$ were missed on the initial ED presentation. There were 114 type A and 80 type B aortic dissections.

Only $20(14.8 \%)$ patients were asked all five questions. Further, no questions or one question was asked of $14.1 \%$ of the patients. The most common initial incorrect diagnosis was acute coronary syndrome (16, 47\%), pulmonary embolism $(5,14.7 \%)$, and stroke $(4,11.7 \%)$ (Table A-1). The quality of history was associated with suspicion for aortic dissection. If all five questions were asked, the physician correctly suspected aortic dissection in 19 of 20 patients (95\%). If more than two questions were asked, $94 \%$ of all aortic dissections were correctly identified. The miss rate was 1 in 17 or $6 \%$. If two or fewer questions were asked, one in five $(20 \%)$ cases was missed. Asking more than two questions resulted in a significant increase in the likelihood of the correct diagnosis $(p<0.01)$, with a sensitivity of $93.3 \%$ (95\% confidence interval $[\mathrm{CI}]$ 82.4-97.6). The most common questions not asked were the severity of pain, duration, and radiation.

\section{DISCUSSION}

Aortic dissection is one of the deadly causes of chest pain. It can present with a myriad of symptoms often overlapping with more common diagnoses. This can result in a significant number being misdiagnosed. ${ }^{3}$ In our study, one in five patients was initially misdiagnosed. The diagnostic test of choice is CT of the aorta. However, this carries a significant radiation burden and results in longer ED stays, in addition to increasing costs. ${ }^{4,7}$ With increased access to CT, the number of imaging studies in the ED has increased, without a decrease in the miss rate. Only 1 in 50 CT scans is actually positive for an aortic dissection. ${ }^{8}$ In the age of clinical decision rules, clinicians rate aortic dissection as the number one priority for developing a new decision tool. ${ }^{9}$ However, could simply improving the quality of history taking improve missed diagnosis and reduce imaging?

This hypothesis-generating study found that a focused history of important pain characteristics was associated with fewer missed cases of AAD. We found that if 
three or more questions were asked, only $6 \%$ of cases were missed, as compared with $22 \%$ if two or fewer questions were asked. Our findings are similar to those of Rosmans' 1998 study, which found that asking three specific pain questions (quality, radiation, and speed of onset of pain) was associated with a reduction in missed cases of AAD. ${ }^{5,10}$

It makes clinical sense that a more complete history has the potential to reduce diagnostic error. In an age of easier access to advanced imaging, history taking is still the keystone of diagnostic accuracy.

\section{LIMITATIONS}

This is a retrospective study, and it is difficult to know whether missing values for history taking truly represent a lack of asking a complete history or documentation. However, even if it does represent a lack of documentation, it speaks to a lack of consideration of aortic dissection. Documentation is often completed at the end of a clinical encounter, with classic features for a condition more likely to be documented if the clinician thinks it is the most likely diagnosis. It could be that reaffirming the importance of documentation could act as a cognitive forcing strategy to help clinicians think about the diagnosis of aortic dissection.

Our population contains patients in whom AAD was identified at some point during their evaluation. Because patients with unrecognized $\mathrm{AAD}$ do not appear in the database and because these patients may, in fact, be unrecognized as a result of atypical presentations, this might have affected our results. In addition, this study was conducted at an academic tertiary care and cardiac referral centre and, thus, could be subject to referral bias.

\section{CONCLUSIONS}

In patients with an eventual diagnosis of $\mathrm{AAD}$, physicians who asked more common pain questions had a better initial identification of cases. Ask and document the character, onset, duration, radiation, and severity in any patient presenting with chest, abdominal, or flank pain. A focused history appears to be important in reducing the likelihood of missing AAD.

Supplementary material: The supplementary material for this article can be found at https://doi.org/10.1017/cem.2019.1.

Acknowledgements: Dr. Ohle was responsible for study conception and oversight; in addition to data analysis and manuscript preparation, he acts as guarantor of the paper, taking responsibility for the integrity of the work, from inception to published article. We acknowledge the help of Justin Um, Lindy Luo, Omar Anjum, and Helena Bleeker in data extraction. Dr. Mc Isaac was involved in the manuscript editing and writing. Dr. Perry provided methodological input and oversight.

Competing interests: None.

\section{REFERENCES}

1. Rosman HS, Patel S, Borzak S, Paone G, Retter K. Quality of history taking in patients with aortic dissection. Chest 1998;114(3):793-5.

2. Harris KM, Strauss CE, Eagle KA, et al. Correlates of delayed recognition and treatment of acute type A aortic dissection: the International Registry of Acute Aortic Dissection (IRAD). Circulation 2011;124(18):1911-8.

3. Finnerty NM, Rodriguez RM, Carpenter CR, et al. Clinical decision rules for diagnostic imaging in the emergency department: a research agenda. Acad Emerg Med 2015;22(12):140616.

4. Ohle R, Anjum O, Bleeker H, Wells G, Perry JJ. Variation in emergency department use of computed tomography for investigation of acute aortic dissection. Emerg Radiol 2018;25 (3):293-8.

5. Ohle R, Um J, Anjum O, et al. High risk clinical features for acute aortic dissection: a case-control study. Acad Emerg Med 2018;25(4):378-87.

6. Hansen MS, Nogareda GJ, Hutchison SJ. Frequency of and inappropriate treatment of misdiagnosis of acute aortic dissection. Am 7 Cardiol 2007;99(6):852-6.

7. Lovy AJ, Bellin E, Levsky JM, Esses D, Haramati LB. Preliminary development of a clinical decision rule for acute aortic syndromes. Am 7 Emerg Med 2013;31 (11):1546-50.

8. Jansen AC, van Aalst-Cohen ES, Hutten BA, et al. Guidelines were developed for data collection from medical records for use in retrospective analyses. F Clin Epidemiol 2005;58 (3):269-74.

9. Ohle R, Kareemi HK, Wells G, Perry JJ. Clinical examination for acute aortic dissection: a systematic review and meta-analysis. Acad Emerg Med 2018;25(4):397-412.

10. Kurabayashi M, Miwa N, Ueshima D, et al. Factors leading to failure to diagnose acute aortic dissection in the emergency room. 7 Cardiol 2011;58(3):287-93. 